\title{
Institutional Downsizing: Impact on Work Satisfaction and Workplace Commitment among Clinical Instructors in Region VI, Philippines:Voices of Struggles
}

\author{
Louie P. Hijalda \\ Center for Educational and Institutional Research, University of San Agustin, Philippines \\ ORCID: 0000-0002-9002-2240
}

Received May 8, 2021; Revised November 11, 2021; Accepted December 13, 2021

\begin{abstract}
Cite This Paper in the following Citation Styles
(a): [1] Louie P. Hijalda , "Institutional Downsizing: Impact on Work Satisfaction and Workplace Commitment among Clinical Instructors in Region VI, Philippines: Voices of Struggles, "Universal Journal of Educational Research, Vol. 10, No. 1, pp. 1 - 13, 2022. DOI: 10.13189/ujer.2022.100101.

(b): Louie P. Hijalda (2022). Institutional Downsizing: Impact on Work Satisfaction and Workplace Commitment among Clinical Instructors in Region VI, Philippines: Voices of Struggles. Universal Journal of Educational Research, 10(1), 1 - 13. DOI: 10.13189/ujer.2022.100101.
\end{abstract}

Copyright $\bigcirc 2022$ by authors, all rights reserved. Authors agree that this article remains permanently open access under the terms of the Creative Commons Attribution License 4.0 International License

\begin{abstract}
Many Philippine schools, colleges and tertiary institutions struggled to restructure their educational institutions with the full implementation of $\mathrm{K}-12$ and the advent of Outcomes-Based Education in Philippine Educational System since 2016 in compliance with the International Qualification Standards utilizing different strategies for their survival and growth. This research aimed to determine the impact of institutional downsizing towards work satisfaction and clinical instructors' workplace commitment in Region VI. The study employed a descriptive-correlational design utilizing a survey method. Qualitative data were obtained to enrich survey results. Ninety-one (91) clinical instructors in various nursing colleges in Region VI, Philippines were chosen as actual participants using a stratified random sampling. Data collected were analyzed using appropriate descriptive, inferential statistics and qualitative analysis. The overall interpretation indicates a moderate level of work satisfaction (grand mean of 3.81) and clinical instructors' workplace commitment (grand mean of 4.20) in Region VI; there is no significant relationship between clinical instructors' workplace commitment and profile variables except for area of assignment $\left(\chi^{2}=16.217, \mathrm{p}=0.013\right)$. There is no significant relationship between institutional downsizing and workplace commitment. However, there is a significant relationship between work satisfaction and
\end{abstract}

workplace commitment $(\chi 2=100.2, p=0.000)$. The study concluded that clinical instructors' perception of the impact of restructuring has little effect on their work satisfaction and workplace commitment but undergone various struggles.

Keywords Institutional Downsizing, Work Satisfaction, Workplace Commitment, Clinical Instructors, Region VI, Philippines

\section{Introduction}

Philippine tertiary institutions are going through a dynamic change and are using different strategies for their struggle, survival and growth. Change is a way of life and the ability to manage change is a key factor in institutional survival and effectiveness. Restructuring is currently the most used strategy being used by tertiary institutions in their effort to survive and compete in the current educational system after the basic education shifted to K-12 which also affected the higher educational institutions and the advent of Outcomes-Based Education in compliance with the International Qualification Standards [1]. Since educational institutions find themselves operating in a more complex, unpredictable, 
and dynamic environment, they employ different strategies to achieve their goals [2] by adjusting their structural hierarchy (restructuring) and redesign administrative functions and responsibilities (reorganization) generally known as downsizing.

Downsizing refers to layoffs that may or may not be accompanied by systematic restructuring programs such as staff reductions, departmental consolidations, office closings, or other forms of reducing payroll expenses [3]. Institutional downsizing is the conscious use of personnel reductions when faced with difficult economic conditions [4], and these changes were described by Lawson and Angle [5] as "trigger events", which initiated knowledge shifts and stir up feelings and emotions that elicited different reactions because the effort of many educational tertiary institutions goes into separation packages and support for lay off employees as a result of downsizing with little attention given to the retained employees who are remaining in educational institutions [6].

The proponents contend that downsizing leads to lower overhead bureaucracy and faster decision making, leading to a positive organization $[7,8]$. However, these was in contradiction to the findings of Ikyanyon [2], Lawson and Angle [5], Perry [9], as cited by Malik, Ahmad, and Hussain [10], which found a number of negative responses exhibited by retained employees of downsizing. The main problems that have been identified are lowered morale, increased workload, ambiguity, threat of job loss, denial, "survivor guilt," lower affective commitment, increased absenteeism, turnover, unproductive workforce. Proponents of downsizing argue that it is an effective strategy, with benefits such as increased performance while detractors point out to negative consequences including performance and productivity declines, decreases satisfaction and adverse effects on remaining employees, such as stress [11]. Furthermore, downsizing has some temporary or immediate advantages such as boosting profits, avoiding bankruptcy, creating new relationships, and re-organization [12]. As Malik, Ahmad, and Hussain [10] stated that after downsizing, the retained employees are subject to a number of adjustments, such as new job descriptions, new procedures and confronted difficult situations including the work overload that causes fatigue and burnout that ultimately leads to dissatisfaction which could challenge the job satisfaction and affect organizational commitment.

Although work satisfaction has received the most attention of all work-related attitudes and organizational commitment has become increasingly recognized in the organizational behaviour literature yet, there are always many employees who are satisfied with their jobs, but dislike the highly bureaucratic organization they work for. In light of the new environment that includes downsizing in relation to advent of K-12 and commencement of CHED Memorandum Order number 46, work satisfaction and commitment has resurfaced as a very important topics of study and concern along with the profile variables namely - age, sex, civil status, educational attainment, monthly salary, length of service and area of assignment.

Different related literature obtained various results using key variables. In terms of work satisfaction, related literature presented that older workers $[13,14]$ are more satisfied than their younger counter parts; sex is not associated with overall work satisfaction (Fall [15], as cited by Hijalda [16]); married workers has a higher degree of job satisfaction than unmarried workers $[17,18$, 19]; employees with higher educational attainment tend to be more satisfied than workers with lower educational level (Griffin as cited by Sharma [19] and Kim [20]); in terms of length of service, workers who have been in the service for a long period of time (Señeres as cited by Hijalda [16], Lopopolo, as cited by Williams [21]); high paid workers are more satisfied than their counterparts [22, 23]; and for area of assignment, workers employed in hospital are less satisfied compared to those assigned in other areas [24, 25, 26].

In terms of workplace commitment, related literature presented that older workers are more committed than younger ones (Tsai [27] as cited by Yu [28]); women are more committed [29, 30]; married workers are more committed [31, 32]; employees with higher educational attainment are more committed (Ahmad, as cited by Hijalda, [16]); Yang, Liu, \& Huang [32] and Hassan [33]; in relation to length of service, employees with more than 5 years of service are more committed $[31,34]$; pay may not be a factor in increasing commitment (Buchanan \& Considine, as cited by Williams [21]); while according to Witt [35]. However, the researcher noticed that majority of all of the related literatures gathered were of foreign origin and very little related literature was identified in relation to the study being conducted - institutional downsizing, work satisfaction and workplace commitment particularly among clinical instructors in any region in a Philippine setting.

Thus, the researcher conducted this study because of the novelty of the study in relation to the impact of Institutional Downsizing towards Work Satisfaction and Workplace Commitment of Clinical Instructors in Region VI Philippines, and the experiences of struggle during downsizing.

\section{Problem Statement}

This study aimed to determine the impact of Institutional Downsizing on Work Satisfaction and Workplace Commitment among Clinical Instructors in Region VI, Philippines and their struggles experienced during downsizing. 


\section{Conceptual Framework}

The conceptual framework of the study as illustrated in the schematic diagram (Figure 1) was anchored on Fritz Heider's Attribution Theory and Rosemary Rizzo Parse's Human Becoming Theory.

Fritz Heider's Attribution Theory basically looks at how clinical instructors make sense of their world, what cause and effect inferences they make about the behavior of others and of themselves.

Rosemarie Rizzo Parse Human Becoming Theory tries to uncover personal meanings of a situation (process of downsizing) and make choices to move forward and choose meanings.

The profile variables used in the study were the clinical instructors' age, sex, civil status, educational attainment, monthly salary, length of service, and area of assignment and experiences which could influence their work satisfaction and workplace commitment to their institution depending on their perception of downsizing.

Institutional downsizing has become a fact of working life as educational institutions struggle to cut costs and adapt to changing market demands but as this strategy achieved its desired results will be based on the profile variables and experiences of the participants.

Work satisfaction was represented in terms of work itself, superior and/or colleague relationship, recognition of work performance and advancements' as a clinical instructor. These were dimensions identified to represent the most important characteristics of a job about which clinical instructors have affective responses (Newstrom [36]).

Workplace commitment was measured in terms of being responsive and innovative professional, culture of excellence and institutional identity. These were dimensions identified that represent the three-component model of Meyer and Allen which were - affective commitment, continuance commitment and normative commitment (Newstrom [36]).

A correlation shall be established between profile variables and institutional downsizing; profile variables and work satisfaction; profile variables and workplace commitment; institutional downsizing and work satisfaction; institutional downsizing and workplace commitment and work satisfaction and workplace commitment, as depicted in double sided arrows. Data gathered in this present study may recommend policies and guidelines relative to institutional downsizing.

Figure 1 illustrates the assumed relationship among the different variables of the study. 


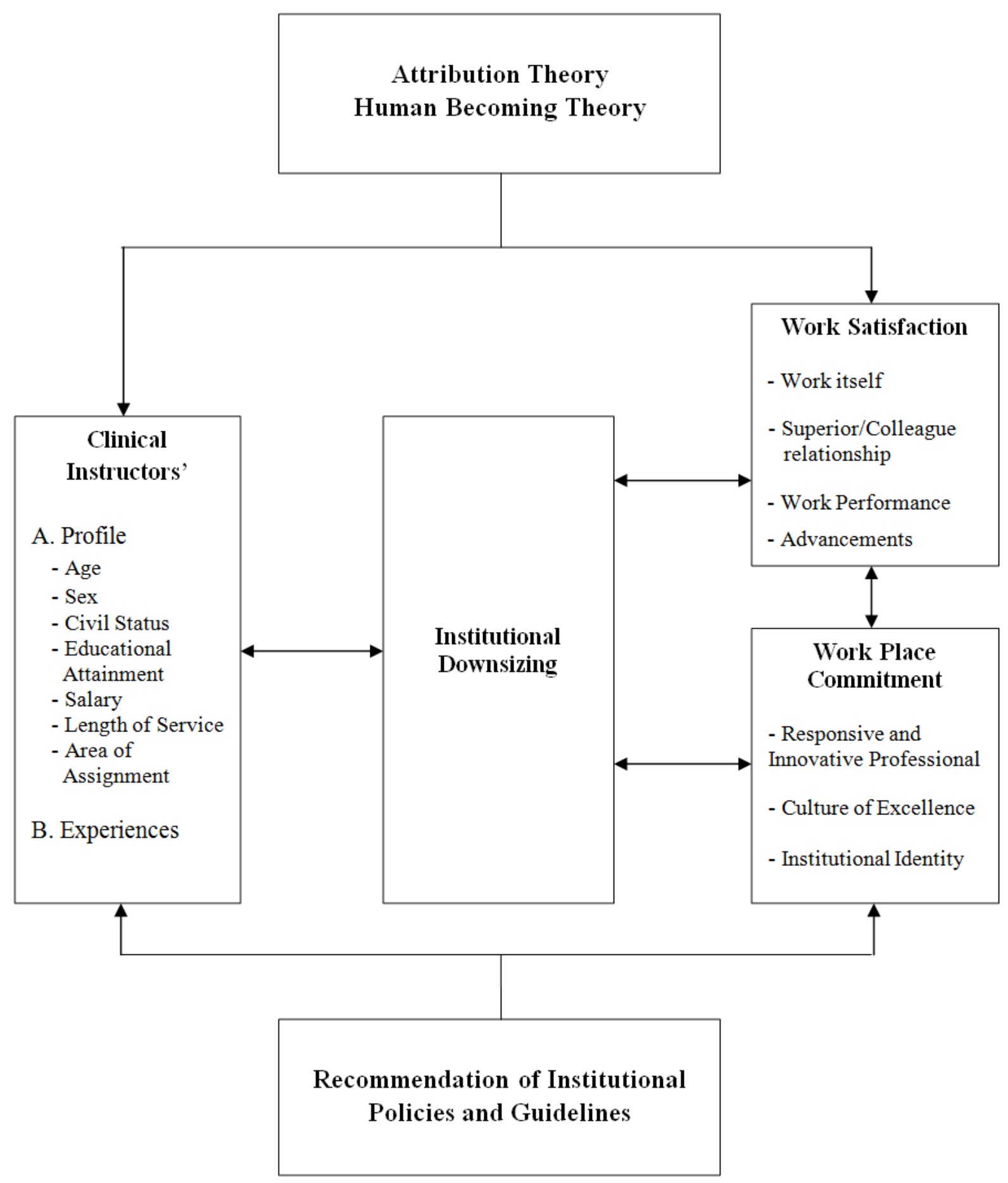

Figure 1. Schematic Diagram of the Conceptual Framework of the Study 


\section{Methods}

\subsection{Research Design}

The study utilized a descriptive-correlational design utilizing a survey method. Qualitative data were obtained to enrich survey results. The study was conducted to higher education institutions offering Bachelor of Science in Nursing in five provinces in Region VI namely - Aklan, Antique, Capiz, Iloilo, and Negros Occidental among retained clinical instructors for Academic Year 2017 2018.

\subsection{Eligibility Criterion}

Eligibility criteria for inclusion of the study were (a) participants are employed in a private Higher Educational Institution (b) with full time status (c) part of AY 2017 2018 (d) and with approval from administration of their institutions .

To further gather the experiences of clinical instructors, Key Informants were identified, five (5) of whom were requested for an in-depth interview. These five (5) participants were selected according to the criteria for inclusion wherein (a) he/she served his/her College of Nursing ten years and above; (b) a full-time faculty and (c) his/her college of nursing must have experienced downsizing last AY $2017-2018$.

\subsection{Research Instrument}

A tailored fit self-made questionnaire was made by the researcher that is relevant to the concerns and needs of the clinical instructors in different Colleges of Nursing in Region VI, Philippines was used to gather the needed data for analysis and was designed in the following order:

Part I is the Letter to the Participants; Part II is Participant's Informed Consent Form; Part III is the Participant's Profile which aims at gathering data on the personal and work-related attributes of the participants. Items on personal and work related attributes included age, sex, civil status, and highest educational attainment, and monthly salary, length of service and area of assignment; Part IV.A.1 is a question designed to determine the reasons for the organizational downsizing as mandated by their institution's administration; Part IV.A.2 is a rating scale which consisted of a 30-item test questions for the Institutional Downsizing Questionnaire to determine the impact of institutional downsizing; Part IV.B is a rating scale consisted of a 40-item test questions for the Work Satisfaction which was patterned and modified from LP Hijalda's Job Satisfaction Questionnaire; in terms of work, superior and/or colleague's relationship, recognition of work performance and advancements designed to determine clinical instructors' job satisfaction; Part IV.C is a rating scale using a 30 -item test questions for
Workplace Commitment which was patterned and modified from LP Hijalda's Organizational Commitment Questionnaire; in terms of culture of excellence, as a responsive, innovative professional and institutional identity designed to determine clinical instructors' workplace commitment.

\subsection{Validity of the Instrument}

The self-made questionnaire was submitted to a five-jury panel member, including a Higher Education Institution's Vice President for Academic Affairs, a Human Resource Associate, a Dean of a College of Nursing, a member of an institution's Ethics' Review Committee, and a Chairperson of a Nursing Research Management Committee to check whether the instrument appropriately covers the topics and the variables intended to be studied and the items adequately represented the subject to be assessed.

\subsection{Reliability of the Instrument}

Since the instrument was researcher made, it was pretested in order to determine the reliability. Using the fishbowl technique, the researcher administered the questionnaire to thirty (30) clinical instructors in two particular College of Nursing in Iloilo City who were not included in the study eventually and was subjected to Cronbach coefficient alpha test to establish its reliability coefficients and the results revealed 0.892 for Institutional Downsizing, 0.960 for Work Satisfaction and 0.836 for Workplace Commitment respectively which indicated that the questionnaire has a high degree of reliability after consultation with a statistician.

\subsection{Data Extraction}

Before asking the participants to fill up the validated questionnaire, a brief orientation on how to fill up the questionnaire; the purpose of the conduct of the study, confidentiality and instructions was given based on the Participant's Information Statement and with the Consent Form. The researcher personally distributed the questionnaire, giving ample time to answer and a specific date was scheduled to retrieve the questionnaires.

For actual interview, the researcher assured the informants that their privacy will be protected. Afterwards, the informants had been given their codified name or aliases in the study, and the results were analyzed and used in the quantitative discussions of the present study.

\subsection{Data Analysis}

After the questionnaires were answered, it was checked for omissions, inconsistency of responses, or incompleteness of information. The results were edited, 
coded, encoded, and data files were created and tabulated, the coded data were entered and stored in a data sheet, then in a computer disk to facilitate retrieval, processing, and statistical manipulations were done and interpreted according to the desired tabular presentation with the use of Statistical Package for Social Sciences software and a statistician was consulted for data analysis.

\subsection{Statistical Analysis}

The quantitative data gathered were processed and subjected to descriptive and inferential statistics. For specific qualitative problem, key informants' interview was used to present the experiences of the participants relative to organizational downsizing.

All data were processed and analysed using the Statistical Package for Social Sciences (SPSS) software, the 0.05 level of significance was adopted as reference for the acceptance or rejection of null hypothesis.

For the transcription, the researcher tried to find statements in the interview about how the key informants were experiencing and listed out these significant statements in order to support analysis and discussion of data gathered. The responses or insights gathered are used to enrich the analysis and discussion of the quantitative data gathered in the present study.

\subsection{Ethical Considerations}

The research protocol was approved by the Research Ethics Review Committee before the conduct of the study and in its entirety; the researcher was sensitive to the principle of allowing no harm to occur to the participants concerned. There was no coercion, and the participants were assured that they were free to withdraw at any stage, should they choose to do so, and voluntarily agreed to sign the Free and Prior Informed Consent (FPIC) as well as the Key Informant Interview. The anonymity and confidentiality of information was upheld. Privacy and confidentiality of the answers were emphasized thereafter and whatever information gathered was used for research purpose only.

\section{Results}

Majority of participants were 41 years old and above
$(65.0 \%)$, female $(88.0 \%)$, married $(88.0 \%)$, with Master's degree $(81.0 \%)$, with a monthly salary of P $21,000.00$ and above $(51 \%)$, having more than 10 years of service $(78.0 \%)$ and assigned in both classroom and related learning experience (69.0\%).

Table 1. Reasons for the Downsizing as Mandated by the Institution's Administration $(\mathrm{n}=91)$

$\begin{array}{cccc}\begin{array}{c}\text { Reasons for } \\ \text { Downsizing }\end{array} & \text { F } & \text { \% } & \text { Rank } \\ \begin{array}{c}\text { Reduction in } \\ \text { Program Demand }\end{array} & 49 & 54.00 & 1 \\ \quad \begin{array}{l}\text { Financial } \\ \text { Performance }\end{array} & 33 & 36.00 & 2 \\ \begin{array}{c}\text { Realignment of } \\ \text { Managerial } \\ \text { Responsibilities }\end{array} & 9 & 10.00 & 3\end{array}$

The reasons for downsizing are related to reduction in program demand $(54.0 \%)$, followed by financial performance and realignment of managerial responsibilities.

Reduction in program demand was the main reason for the institutional downsizing in relation to the full implementation of K-12 which resulted in unavailability of first year students for AY 2016-2017, no first year and second year for AY 2017-2018 and no third-year students for AY 2018-2019. This led to less nursing students' enrolment and decrease number of nurse educators in relation to unfavourable market conditions, which force heads of institutions to consider realignments or mergers of programs as a single entity, change in management for financial sustainability and organizational restructuring.

The result conforms to the study of Ikyanyon [2] which states that educational institutions facing a more complex, unpredictable, and dynamic environments employ different strategies to achieve their goals by adjusting their structural hierarchy (restructuring) and reorganization to improve productivity, and/or competitiveness which is seconded by Gandolfi and Hansson [4], wherein this practice is an attempt to improve its organizational efficiency and effectiveness during difficult economic conditions and supported by the study of Datta, Basuil, Guthrie, and Pandey [37] and Kinanga and Cheruiyut [6 ]. However, these changes were described by Lawson and Angle [5], as "trigger events" which serve to initiate cognitive shifts and stir up feelings and emotions that elicit reactions to the changes concerned. 
Table 2. Level of Work Satisfaction of the Participants: Advancements as a Clinical Instructor $(n=91)$

Item
1. I am given freedom to share with colleagues' skills
and talents in the form of team teaching to learn
various ideas.
2. My superiors give a progress review feedback of my
performance every semester.
3. I am motivated to grow professionally through
seminars /trainings conducted by the school or college.
4. I am granted with the benefits or reward for a
graduate degree earned.
5. The institution gives me opportunities to utilize my
skills and talents.
6. I availed school's financial support for scholarship
programs.
7. There is a formal career planning that happens in my
workplace.
8. I am given opportunity for training for better
position or promotion in the future.
9. I am supported by the administration on educational
tours pertinent to my subject taught.
10. I am extended financial support for the purchase of
high-tech gadgets for classroom use.
Grand Mean = 3.42 Slightly Satisfied

Mean

3.65

3.58

3.56

3.54

3.54

3.43

3.37

3.30

3.25

3.01

Grand Mean $=3.42$ Slightly Satisfied

$\begin{array}{cc}\text { Rank } & \text { Interpretation } \\ 1 & \text { Moderately Satisfied } \\ 2 & \text { Moderately Satisfied } \\ 3 & \text { Moderately Satisfied } \\ 4.5 & \text { Moderately Satisfied } \\ 4.5 & \text { Moderately Satisfied } \\ 6 & \text { Slightly Satisfied } \\ 7 & \text { Slightly Satisfied } \\ 8 & \text { Slightly Satisfied } \\ 9 & \text { Slightly Satisfied } \\ 10 & \text { Slightly Satisfied }\end{array}$

are bogged down with revising computers and paper works using online databases: CINAHL, ERIC, GOOGLE scholar, MEDLINE, and Science direct open access searching from 2015 to 2018, as well as grading papers which usually takes from several hours to days to finish, depending on the number of students.

The length of the instructional module design with desirable characteristics of OBE focusing on "field centeredness", broad based decision making, specificity, knowledge development emphasis, and learners' lifelong learning [38], being responsive to distinct trends such as educational system reforms, technological utilization, and innovative teaching strategies.

Clinical Instructors create an innovative virtual environment in the classroom, laboratory and clinical settings that facilitate student learning and the achievement of desired cognitive, affective and psychomotor outcomes using assessment and evaluation strategies (UAES) which implies the use of a variety of strategies to assess and evaluate student's learning in the classroom, laboratory and clinical settings, as well as all domains of learning.

The clinical instructors are required to participate in updated and innovative online Curriculum Design and Evaluation of Program Outcomes (PCDEPO), reflecting contemporary health care trends and preparation of graduates to function effectively in the health care environment. Clinical instructors acknowledge that engagement in scholarships is an integrated component of the faculty role and that teaching itself is a scholarly activity and also recognize how political, institutional, social and economic forces impact their role and their satisfaction [39], considering that the Philippines' work satisfaction level dropped from 5.25 in 2016 to its current 
rating of 4.97 on a 10-point scale, wherein the key factors associated with unhappiness at work are lack of career development and training opportunities, as well as the management style of a company's leadership team [40].

Locke, as cited by Newstrom [36], gives a comprehensive definition of work satisfaction as involving cognitive, affective, and evaluative reactions or attitudes. He stated that it is a pleasurable or positive emotional state resulting from the appraisal of one's work or work experience. Furthermore, he stated that is a result of employees' perception of how well their work provides those things that are viewed as important.

Furthermore, work satisfaction is the degree of a workers' affective orientation toward the work role occupied in the institution. This is a complex construct and is often measured as a global attitude of an employee toward his or her work [41].

Work satisfaction is considered a critical factor in health care settings because there is strong empirical evidence to support a causal relationship between job satisfaction, staff turnover and absenteeism. The evidence suggests that when nurses' work satisfaction is low, retention of staff is also low and staff turnover, and absenteeism increases which causes substandard in the health care delivery.

The institutions need to strengthen its human resources to better deliver efficient and quality services and communication seemed to be an important aspect for the participants of the study. Honest, clear and correct information is important for them to understand the urgency of the situation - financial sustainability considering that budget constraints play a major role in the terms identified with the lowest scores. Administrators need to explain to the employees that majority of the Colleges of Nursing are considered as cost centers and not profit centers anymore, thus budget allocations focuses on priority programs and personnel and in relation to educational tours, they need to be informed that such activity is allowed upon compliance of all requirements set by the Commission on Higher education and the institution itself.

The computed value of $\chi^{2}=100.2, p=0.000$ shows that there is a significant relationship between work satisfaction and workplace commitment. This means that participants who were highly satisfied with their job, the more likely that they are committed to the workplace. There is a statistically significant association between work satisfaction and workplace commitment.

Majority of the participants (75.0\%) who were assigned both in the classroom and Related Learning Experience (RLE) have moderate commitment, while there is equal proportion of the participant who had a classroom assignment (55.0\%) and those in RLE (53.0\%) still have moderate commitment towards their organization. A small proportion of participants was assigned in RLE $(17.0 \%)$ and those assigned in classroom setting $(9.0 \%)$ perceived having a slight commitment towards their organization.

Possible reason is about credibility of the professional image of nursing and the acknowledgement of duties and responsibilities of clinical instructors in relation to the resignations of nursing colleagues. They, the remaining clinical instructors need to maintain the nursing education standards and will not affect the operational requirements of the college. Their commitment is being challenges to have enough skilled and professionally qualified clinical instructors to teach relevant nursing disciplines and to follow-up nursing students in the clinical area or community setting.

According to Witt [35], individual worker ranking their occupation identification highly indicated a higher commitment to the workplace. Commitment and performance could lead to positive relationship and work mood if the concerns are properly addressed by counseling and in-service trainings for self-awareness, positive coping strategies and stress management techniques.

Table 3. Relationship between Workplace Commitment and Area of Assignment $(n=91)$

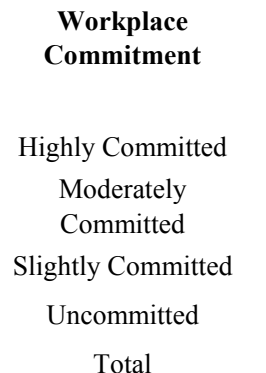

\begin{tabular}{cc}
\multicolumn{2}{c}{ Classroom } \\
F & $\%$ \\
4 & 36.00 \\
6 & 55.00 \\
1 & 9.00 \\
0 & 0.00 \\
11 & 100.00
\end{tabular}

Interpretation; $\chi^{2}=16.217, \mathrm{p}=0.013$ (Significant)

$\begin{array}{cc}\begin{array}{c}\text { Area of Assignment } \\ \text { Related Learning } \\ \text { Experience }\end{array} \\ \text { F } & \% \\ 4 & 24.00 \\ 9 & 53.00 \\ 3 & 17.00 \\ 1 & 6.00 \\ 17 & 100.00\end{array}$

$\begin{array}{cc}\text { Both Classroom and } & \text { RLE } \\ \text { F } & \% \\ 16 & 25.00 \\ 47 & 75.00 \\ 0 & 0.00 \\ & 0 \\ 63 & 100.00\end{array}$

\begin{tabular}{cc}
\multicolumn{3}{c}{ Total } \\
F & $\%$ \\
24 & 26.00 \\
62 & 69.00 \\
4 & 4.00 \\
0.00 & 1 \\
91 & 100.00
\end{tabular}


Table 4. Relationship between Work Satisfaction and Workplace Commitment $(n=91)$

\begin{tabular}{|c|c|c|c|c|c|c|c|c|c|c|}
\hline \multicolumn{11}{|c|}{ Job Satisfaction } \\
\hline \multirow[t]{2}{*}{$\begin{array}{l}\text { Workplace } \\
\text { Commitment }\end{array}$} & \multicolumn{2}{|c|}{ Dissatisfied } & \multicolumn{2}{|c|}{ Slightly Satisfied } & \multicolumn{2}{|c|}{$\begin{array}{l}\text { Moderately } \\
\text { Satisfied }\end{array}$} & \multicolumn{2}{|c|}{ Very Satisfied } & \multicolumn{2}{|c|}{ Total } \\
\hline & $\mathrm{F}$ & $\%$ & $\mathrm{~F}$ & $\%$ & $\mathrm{~F}$ & $\%$ & $\mathrm{~F}$ & $\%$ & $\mathrm{~F}$ & $\%$ \\
\hline $\begin{array}{c}\text { Highly } \\
\text { Committed }\end{array}$ & 0 & 0.00 & 2 & 10.00 & 18 & 28.00 & 4 & 67.00 & 24 & 27.00 \\
\hline $\begin{array}{l}\text { Moderately } \\
\text { Committed }\end{array}$ & 0 & 0.00 & 16 & 80.00 & 44 & 69.00 & 2 & 33.00 & 62 & 68.00 \\
\hline $\begin{array}{l}\text { Slightly } \\
\text { Committed }\end{array}$ & 0 & 0.00 & 2 & 10.00 & 2 & 3.00 & 0 & 0.00 & 4 & 4.00 \\
\hline Uncommitted & 1 & 100.00 & 0 & 0.00 & 0 & 0.00 & 0 & 0.00 & 1 & 1.00 \\
\hline Total & 1 & 100.00 & 20 & 100.00 & 64 & 100.00 & 6 & 100.00 & 91 & 100.00 \\
\hline
\end{tabular}

Interpretation: $\quad \chi^{2}=100.2, p=0.000$ (Significant)

There was a higher proportion of participants who were slightly satisfied $(80.0 \%)$ than those participants who were moderately satisfied $(69.0 \%)$ and very satisfied $(33.0 \%)$ who were moderately committed to the organization, while a higher proportion of those participants $(67.0 \%)$ who were very satisfied compared with those participants who were moderately satisfied $(28.0 \%)$ and who were highly committed to the workplace. The results showed that participants who were highly satisfied with their work, the more likely that they are committed to the workplace. There is a statistically significant association between work satisfaction and workplace commitment.

The research study anchored to Attribution Theory by Fritz Heider, which proposed that what worker perceived and believed about what they saw dictated how they will act; it provides an explanation about the cause-and-effect inferences about behaviour of others and themselves.

In relation to the study, clinical instructors who did not receive the right amount of recognition for work, not recognize for long service rendered nor rewarded with any incentive for awards received in local or national competition, inadequate financial support for scholarship programs, no formal career planning, low salary, having inadequate resources (e.g. tools, equipment, supplies), having extra hours beyond what is legally mandated, with many work load assignments, inconsistencies in implementing college policies and job stress suffer career setbacks that can greatly, and adversely affect motivation, satisfaction and productivity that may lead to resignations and low morale and less affective commitment.

This is critical to management because perceived causes of behavior may influence supervisors and faculty's judgments and actions. Clinical instructors who perceived the cause of their success to be outside of their control may be reluctant to attempt new tasks and may lose motivation to perform well in the workplace. Conversely, clinical instructors who attribute their success to themselves are more likely to have high motivation for work, they feel valued by the organization for their contributions, their self-esteem is increased, and they are more committed to the quality of what they produce and to the growth of the organization.

The empirical revelations are important to Human Resource Management and administrators, since academic personnel seem to value intrinsic factors the most. The analysis of different elements of job satisfaction reveals the importance of job characteristics like the work itself, promotional opportunities and co-workers for enhancing clinical instructors' job satisfaction.

\section{Discussion}

Institutional downsizing was implemented because of the reduction in program demand and financial sustainability especially after the full implementation of $\mathrm{K}-12$, there is a need to re-engineer the educational process to maximize productivity, maintain if not increase effectiveness and efficiency, and however, it was regarded as a threat to the clinical instructors, which elicited certain psychological states like denial of the process of downsizing, feelings of uncertainty, low morale, the professional image of nursing had been negatively affected, according to the findings of Ikyanyon [2], Lawson and Angle [5], Perry [9], as cited by Malik, Ahmad, and Hussain [10], which found a number of negative responses exhibited by retained employees of downsizing. The main problems that have been identified are lowered morale, increased workload, and ambiguity, threat of job loss, denial, "survivor guilt", lower affective commitment and unproductive workforce.

Five stages of loss, namely denial, anger, bargaining, depression, and acceptance as propounded by Kubler-Ross were found to have been experienced. 


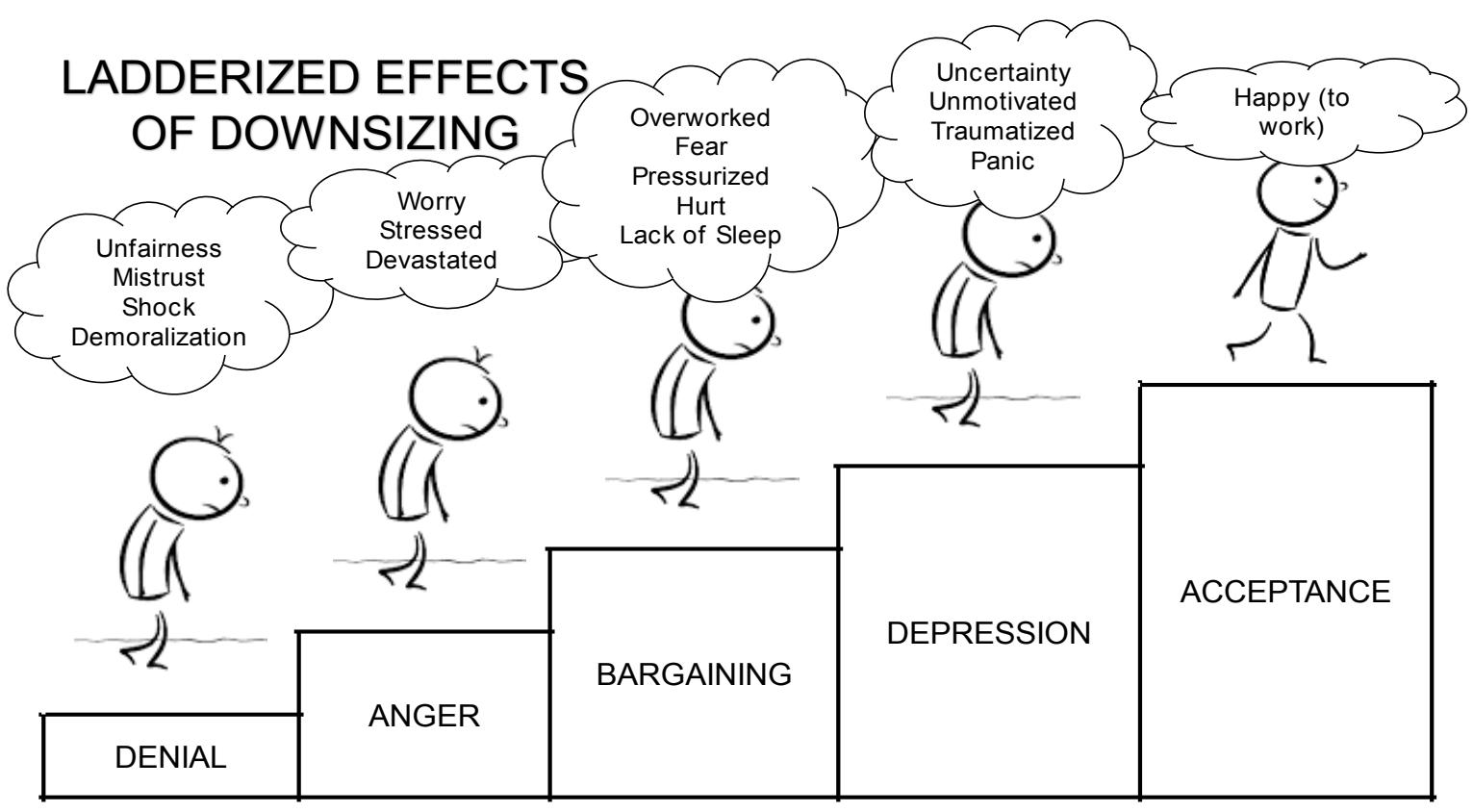

Figure 2. Ladderized Effects of Downsizing

As the change seemed to be unreal, it was initially denied. The insensitive way in which some authorities dealt with the situation may have elicited anger. Feelings of worthlessness with regard to the situation rebounded on the family relationships, as well as on their levels of work motivation and productivity. There was an opportunity for bargaining in the form of effective participation and communication with the administrators and acceptance was evident in relation to their feelings of powerlessness.

Affective experiences of anxiety, depression and emotions were found to have occurred. Such experiences affected the clinical instructors holistically and had an impact on their personal, professional, and working life which found a number of negative responses exhibited by retained employees of downsizing such as lowered morale, increased workload, ambiguity, threat of job loss, denial, "survivor guilt," lower affective commitment, increased absenteeism, turnover, unproductive workforce. The result is being supported by the study of Mujtaba and Senathip (2020) [12], which states that the disadvantages of downsizing in an organization can include reduced skilled workers and low morale, as the employees experience mixed emotions, dismay, stress, guilt, or even envy. In addition, downsizing can reduce existing employees' satisfaction and commitment to the organization, which can result in lower performance.

Furthermore, after downsizing, the retained employees are subject to a number of adjustments, such as new job descriptions, new procedures and confronted difficult situations including the work overload that causes fatigue and burnout that ultimately leads to dissatisfaction which could challenge the job satisfaction and affect organizational commitment.
Concerns regarding the professional image of the nurse were expressed, related to the loss of skilled clinical instructors resulting from resignations and involuntary redeployment. In a nursing college, there must be enough skilled and professionally qualified clinical instructors to teach all the relevant nursing disciplines and to follow-up in clinical setting. Clinical instructors are less willing to take risks in their work environment and the standard of continuous education and professional development may be adversely affected. The perception of the loss of interpersonal relationships tends to bring about feelings of loss of attachment, esteem and support.

This is critical to management because perceived causes of behavior may influence supervisors and faculty's judgments and actions. Clinical Instructors who perceived the cause of their success to be outside of their control maybe reluctant to attempt new tasks and may lose motivation to perform well in the workplace. Conversely, clinical instructors who attribute their success to themselves are more likely to have high motivation and willing to work, they feel valued by the organization for their contributions, their self-esteem is increased, and they are more committed to the quality of what they produce and to the growth of the organization.

\section{Conclusions}

The research study anchored to Attribution theory by Fritz Heider, which proposed that the people perceived and believed about what they saw dictated how they will act; it provides an explanation about the cause-and-effect inferences about behaviour of others and 
themselves.

In relation to the study, clinical instructors who did not received the right amount of recognition for work, not recognize for long service rendered nor rewarded with any incentive for awards received in local or national competition, inadequate financial support for scholarship programs, no formal career planning, low salary, having inadequate resources and others adversely affect motivation, satisfaction and productivity that may lead to resignation and low morale and less affective commitment.

This is critical to management because perceived causes of behaviour may influence supervisors and faculty's judgments and actions. Clinical instructors who perceived the cause of their success to be outside of their control maybe reluctant to attempt new tasks and may lose motivation to perform well in the workplace.

The study concluded that clinical instructors' perception of the impact of the institutional downsizing has little effect on their work satisfaction and workplace commitment and that institutional downsizing has no significant relationship with work satisfaction and workplace commitment among clinical instructors in Region VI, Philippines.

Future studies may consider having a bigger area for study to further generalize the findings and to measure if there is a significant relationship and/or difference between geographical regions in the Philippines. The use of other statistical tool is also suggested as well as cost effectiveness of downsizing, and more research on the link between downsizing, work satisfaction, other commitment types and different job attitudes by considering process phases (before, during, after) of implementations.

\section{Limitations of the Study}

One limitation to this study is the sample size. May consider having a bigger area for study to further generalize the findings and to measure if there is a significant relationship and/or difference between geographical regions in the Philippines.

\section{Recommendations}

In the light of the aforementioned conclusions derived from this study, the following recommendations are presented:

Commission on Higher Education, may emphasize the process of monitoring and measuring the nursing college and/or program in terms of its governance and management; quality of teaching and learning; professional exposure, research, creative work; support for students and its relationship to the community.
The commission may exercise its regulatory jurisdiction to ensure that only those schools with compliant nursing programs will be allowed to operate in relation to Section 8 of RA 7722. The CHED-PRC Monitoring Team needs to ensure that there are mechanisms, procedures and processes in place to ensure that the desired quality improvement is adapted especially for those HEIs' offering board programs.

Higher Education Institutions' Administrators, may give an emphasis on improvement of both job satisfaction and commitment like benchmarking to different nursing colleges to observe their best practices in terms of governance and management; teaching and learning; professional exposure and research; student's support and community involvement.

A consultation and or dialogue with administrators regarding budget allocation and other work-related concerns for the improvement of the faculty and the program it may be advanced. They may assess their knowledge regarding the effect of work engagement and how to enhance clinical instructors' personal resilience.

They may review and assess the ratio of workload, curricular and co-curricular assignments should be equal to all so as to maximize the skills of the clinical instructors for maximum output. Review the scheme for meal and transportation allowances, procurement of tools, equipments and supplies for skills laboratory and related learning experiences and distribution of co-curricular assignments to nursing colleagues and to come up with attractive reasons to make faculty members stay in their job longer, like hazard pay and improvement in promotion policy may also be done.

It is also recommended that research orientation of clinical instructors be enhanced through seminars and workshops; minimize work related stress through stress management and try looking into ways of improving total benefit package, like meal allowance for lecturers and hazard pay in Related Learning Experiences as well as reviewing the salary scheme for those nurse lecturers and those with RLE only.

Furthermore, the emphasis is put on reviewing the policies and guidelines that will enhance effective performance in the working condition especially in community setting like immersion guidelines and improvement on the CHN RLE plan of activities; a need for greater protection and security in the workplace by having consultative dialogue with the community officials with RLE affiliations, regarding hazard pay and health insurance.

Human Resource Director may give an emphasis on improvement of both work satisfaction and workplace commitment of employees like reviewing the structuring process of reduction of employees as a downsizing strategy in consonance with the collective bargaining agreement or faculty handbook, instituting evaluative studies on sources of work-related stress and job 
satisfaction.

It is recommended further that the HR department need to review and strengthen activities like rest and recreation among faculty members, personnel self-awareness activities conduct evaluative studies and feed backing about performance and supervision, use different types of rewards for performance, conduct individual counselling, rather than in the form of group sessions; and update appraisal on career development and promotion.

HR department also needs to review their policy on financial assistance especially regarding national and international seminars and purchase of gadgets for classroom use; a review is also needed regarding scholarship programs considering that some clinical instructors still had bachelors' degree and some that have doctorate degree were not aligned with nursing.

Clinical Instructors need programs that might be made in enhancing their work satisfaction and workplace commitment. They need to have a schedule day for a dialogue with the administrators in coordination with the HR department about their concerns like financial assistance towards seminars, scholarship programs, and benefits, work-related problems and colleague relationship however, they also need to cooperate, uphold and defend the academic legacy and identity of the institution they work with.

Future researchers The use of other statistical tool is suggested, and there can be more research on the link between downsizing, work satisfaction, other commitment types and different job attitudes by considering process phases (before, during, after) of implementations.

Researches with cultural or sectorial comparative patterns are also needed for future studies in order to achieve a completely understanding on differences or similarities between variables. Additionally, different variables like job insecurity, employee morale, resilience, burn-out, coping mechanisms, leadership-management styles of clinical instructors, existence of alternative job opportunities, conflict management, supervisory support and organizational change might be added that can influence the relationship of institutional downsizing, work satisfaction and workplace commitment to further substantiate the findings of this research study and to be conducted in other regions in local setting.

\section{REFERENCES}

[1] Sana, E. A., "Approaches in teaching and assessing in outcome-based learning," Philippine Journal of Nursing Education vol. 26, pp. 51-62, 2014.

[2] Ikyanyon, D. N., "Perceptions of organizational downsizing and job satisfaction among survivors in nigerian banks," Management. Scientific and Academic Publishing. 593.j.mm2012204.04, 2012.

[3] Heil, Kurt. Downsizing and Rightsizing Reference for Business. File:///G.:/ downsizing and rightsizing strategy,organizations,levels,system,advantages,type,comp any, 2019.

[4] Gandolfi, F. \& Hansson, M., "Causes and consequences of downsizing towards an integrative framework, "Journal of Management and Organization 17.4, 2011.

[5] Lawson, R. \& Angle, A., "Does downsizing strategy affect the retained employee performance," Journal of Human Resources Management Research, IBIMA Publishing. Retrieved fromhttp://www.ibimapublishing.com/journals/J HRMR/jhrmr.html, 2008.

[6] Kinanga, R. \& Cheruiyot, A. C., "Does downsizing strategy affect the retained employees' performance," Journal of Human Resources Management Research. Volume 2015. IBIMA Publishing, 1-7, 2015.

[7] Tsai, C and Yen, Y., "A model to explore the mystery between organizations' downsizing strategies and firm performance: integrating the perspectives of organizational change, strategy and strategic human resource management," Journal of Organizational Change Management, vol. 21, no. 3, pp. 367-384, 2008.

[8] Gillet, N., Colombat, P., \& Michinov, E., "Procedural justice, autonomy support, work satisfaction, organizational identification and job performance: the mediating role of need satisfaction and perceived organizational support," Journal of Advanced Nursing, 69 (11), 2560-2571, 2013.

[9] Perry, L., "Organizational commitment," Journal of Advanced Nursing. 68, (7), 1441-1442, 2012.

[10] Malik, M. Ahmad, A. \& Hussain,S., "How downsizing affects the job satisfaction and life satisfaction of layoff survivors," African Journal of Business Management (4):3564 -3570, 2010.

[11] Zorn, M., Norman, P., Butler, F.C., and Bhussar, M., If you think downsizing might save your company, think again. Harvard Business Review, 2017.

[12] Mujtaba, B. and Senathip, T. Layoffs and downsizing implications for the leadership role of human resources. Journal of service science and management, 13, 209-228.doi: 10.4236/jssm.2020.132014, 2020.

[13] Lee, P., Miller, M. \& Rosen, "College nursing faculty job satisfaction, and retention: A national perspective," Journal of Professional Nursing Vol. 33, Issue 4 pp 261-266. Published by Elsevier, Inc., 2017.

[14] Luthan, F., "Organizational behavior," (11th Ed.), Boston: Irwin McGraw-Hill, 2008.

[15] Fall, "Determinants of job satisfaction of municipal government employees," State and Local Government Review. 33 (3), 173-84, 2011.

[16] Hijalda, Louie P., "Job satisfaction and organizational commitment among the University of San Agustin nursing faculty," Master of Arts in Nursing thesis, Iloilo City. Saint Paul University Iloilo, 2011.

[17] Robinson, J., "Staff commitment in the correctional service of Canada," http://www.csc-scc.gc.ca, 2009. 
[18] Knerr, M., "An empirical analysis of the relationship between marital status and job," Retrieved from http://nursing spectrum.com, 2008.

[19] Sharma, J. C., "Job satisfaction of university teachers: An empirical study," Journal of Services Research 9 (2), 51, 2010.

[20] Kim, Y., "The determinants of public officials' job satisfaction," - The case of Korean public officials in the cadastral administration, International Conference, FIG Working Week, Seoul, Korea. Retrieved from www.new technology for a new century.htm, 2008.

[21] Williams, J., "Job satisfaction and organizational commitment," Purdue University Indianapolis. Industrial / Organizational Psychology, 81, 411-420, 2008.

[22] Sverke, M., Hellgren, J., Näswall, K., Göransson, S., \& Öhrming, J., "Employee participation in organizational change: Investigating the effects of proactive vs. reactive implementation of downsizing in Swedish hospitals, Zeitschrift für Personalforschung (ZfP)," 22 (2), 111-129, 2008.

[23] Lamm, E. \& Gordon, J. R., "Empowerment, predisposition to resist change, and support for organizational change, Journal of Leadership \& Organizational Studies, 17(4), 426-437, 2010.

[24] Davis, B., "Comparison of job satisfaction between experienced medical surgical nurses and experienced critical care nurses," Medsurg Nursing Retrieved from http://findarticles.com, 2009.

[25] Beiring, S., "Occupational stress, job satisfaction, and working environment among Icelandic nurses: a cross sectional questionnaire survey, Retrieved from http://www.ncbi.nlm.nih.gov/pubmed, 2008.

[26] Cowman, W., "Job satisfaction in psychiatric nursing," Retrieved from http;//www.ingentaconnect.com, 2008.

[27] Tsai, "Job satisfaction," Retrieved from http://abcnews.go.com.Health Stress, 2008.

[28] Yu Ching, H., "Job satisfaction and organizational commitment among faculty at taiwan's higher education institutions (China)," Retrieved from http://www.esrnexus. com, 2008.

[29] Mathieu \& Zajac, "Correlates and predictors to organizational commitment in China," Journal of Asia
Business Studies, (5), 11-24, 2008.

[30] Velickovic, V., Jovic, S., \& Mladenovic, J., "Organizational commitment and job satisfaction among nurses in Serbia," Nursing Outlook, 62 (6), 415, 2014.

[31] Stum, D., "Re-inventing employee commitment," Retrieved from http://www.nehra.com, 2008.

[32] Yang, J., Liu, Y., \& Huang, C., "Impact of empowerment on professional practice environments and organizational commitment among nurses," International Journal of Nursing Practice. 19 (1), 44-55, 2013.

[33] Hassan, S., "Optimism, self-confidence and work engagement of workers in accounts and nursing profession-gender difference," Retrieved from http://www.iobm.edu.pk/PBR/PBR1007, 2010.

[34] Ahmad, A., "Influence of communication satisfaction on organizational commitment of academic staff of universities kebangsaan Malaysia," Retrieved from http://2008.managementconference.com, 2008.

[35] Witt, A., "Reactions to the work assignment as predictors of organizational commitment: The Moderating Effect of Occupational Identification," FAA Civil Institute, USA. Retrieved from http//www.sciencedirect.com, 2008.

[36] Newstrom, J., "Organizational behavior: human behavior at work," 14th Edition. McGraw-Hill Edition, 2 Penn Plaza, New York,NY 10121, 2015.

[37] Datta, D., Basuil, D., Guthrie, J.P., and Pandey, A., "Causes and effects of employee downsizing: a review and synthesis," Journal of Management, vol. 36 no. 1, pp. 281-348, 2010

[38] Lorenzo, F., Strategies and directions in nursing to meet the Philippine education quality assurance standards www.adpen.org, 2014.

[39] Moreno-Lacalle, R., Integrative review of outcomes-based education in nursing. Philippine Journal of Nursing Education Vol. 26, pp. 51-62, 2016.

[40] JobStreet.com., 2017 Job Happiness Index. Retrieved from http://wwww.jobstreet.com.ph, 2017.

[41] Derby-Davis, M. J., Predictors of nursing faculty's job satisfaction and intent to stay in academe. Journal of Professional Nursing. Vol. 30 No. 1, pp. 19-25. Published by ElsevierInc., 2014. 